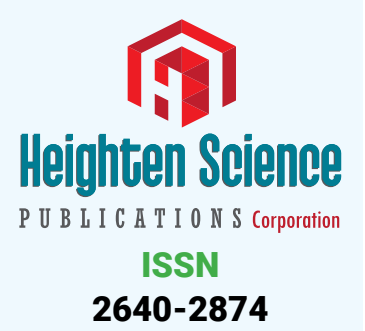

2640-2874

\title{
Pathological Effects of Cypermethrin on the Testes and Accessory Sexual Glands of Yankasa Rams
}

\author{
Ubah Simon ${ }^{1 *}$, Ogwu David ${ }^{1}$, Rekwot Peter ${ }^{1}$, Rwuaan Joseph ${ }^{1}$, \\ Chibuogwu ljeoma² and Njoku Celestine ${ }^{3}$ \\ 'Department of Theriogenology and Production, Faculty of Veterinary Medicine, Ahmadu Bello \\ University, Zaria, Nigeria \\ ${ }^{2}$ Animal Science Department, Faculty of Agriculture, University of Abuja, Abuja, Nigeria \\ ${ }^{3}$ Department of Veterinary Pathology, Faculty of Veterinary Medicine, Ahmadu Bello University, \\ Zaria, Nigeria
}

\begin{abstract}
*Address for Correspondence: Ubah Simon, Department of Theriogenology and Production, Faculty of Veterinary Medicine, Ahmadu Bello University, Zaria, Nigeria, Tel: +2348036097428; Email: drubah2000@yahoo.com
\end{abstract}

Submitted: 06 June 2018

Approved: 19 June 2018

Published: 20 June 2018

Copyright: @ 2018 Simon U, et al. This is an open access article distributed under the Creative Commons Attribution License, which permits unrestricted use, distribution, and reproduction in any medium, provided the original work is properly cited.

Keywords: Pathology; Cypermethrin; Testes; Accessory sex glands; Rams

\section{Abstract}

An investigation into the pathological lesions of Cypermethrin on the testes, accessory sexual and pituitary glands of Yankasa rams was carried out. Sixteen Yankasa rams aged 18 - 30 months and weighing between $21.5-46.5 \mathrm{~kg}$ were used. The $16 \mathrm{rams}$ were divided equally into two groups ( $A$ and $B$ ) $A$ served as the treatment group while B served as the control. Group (A) were given Cypermethrin (3\%) at the dose rate of $3 \mathrm{mg} / \mathrm{kg}$ $(0.1 \mathrm{ml} / \mathrm{kg})$ body weight, topically. Group (B) rams were given distilled water at the same dose rate and route. These treatments were repeated every two weeks for a period of 12 weeks. The rams were sacrificed at the end of 12 weeks and the following organs (testes, pituitary, vesicular and prostate glands), were collected and weighed, gross pathological lesions were observed and photographs were taken. The samples were kept for histopathology. Results showed that there were no gross pathological lesions found on the testes, pituitary, prostate glands and the seminal vesicles of both groups. The mean weight of the pituitary gland, the prostate glands and the seminal vesicles of the treated and control groups were statistically not significant $(P>0.05)$. No histologic lesions were found on them. The mean testicular weights of the treated $(143.81 \pm 7.71 \mathrm{~g})$ and the control $(130.43 \pm 0.63 \mathrm{~g})$ were significantly different $(P<0.05)$. There was a reduced number of spermatozoa in the lumen of the seminiferous tubules of the treated group. It was concluded that Cypermethrin reduced spermatozoa in the lumen of the seminiferous tubules.

\section{Introduction}

Cypermethrin is toxic not only for insects but also for mammals [1,2]. Clinical signs like muscular tremors, ataxia, and weakness of limbs, convulsions, coma and death from respiratory depression have been reported in animals after ingesting high doses of Cypermethrin [3]. Incoordination, muscular tremors, jerky movements, ataxia, staggering gait and dizziness were observed in dose dependent manner in Cypermethrin treated rabbits [4]. The nervous signs started about 10 minutes after each Cypermethrin treatment and persisted mostly for 30 minutes to two hours. Similar nervous signs have been reported by different workers [4]. Long-term feeding studies with laboratory animals have shown that Cypermethrin causes adverse effects. In rats, it caused reduced growth rate and increased liver weight. In mice, it caused reduced weight gain, mild anemia, and increased liver weight. In dogs it caused loss of appetite, incoordination and tremors. In rabbits, it caused pathological changes in the thymus, liver, adrenal glands, lungs and skin [5]. Symptoms of Cypermethrin poisoning in humans include facial burning, tingling (called paraesthesia), dizziness, headaches, nausea, anorexia, fatigue and loss of bladder control. Symptoms of muscle twitching, drowsiness, coma, and seizures are manifested with greater exposure to Cypermethrin. Symptoms of Cypermethrin toxicity in laboratory animals include pawing and seizures

How to cite this article: Simon U, David O, Peter R, Joseph R, ljeoma C, et al. Pathological Effects of Cypermethrin on the Testes and Accessory Sexual Glands of Yankasa Rams. Arch Pathol Clin Res. 2018; 2: 006-012. https://dx.doi.org/10.29328/journal.apcr.1001006 
[5]. The median oral lethal dose (the dose that kills 50 percent of a population of test animals $L D_{50}$ ) is variable. In rats the $L_{50}$ can vary from 250 to over 4,000 milligrams per kilogram $(\mathrm{mg} / \mathrm{kg})$ of body weight. This variability is partly due to the solvents used in the test and due to variability in the proportions of Cypermethrin isomers [5]. Pyrethroid insecticides, including Cypermethrin, can be broken down by enzymes called esterases. The same enzymes are inhibited by organophosphate insecticides. If the two kinds of insecticides are used together, Cypermethrin is not broken down as fast as it should be; the result is that the two kinds of insecticides are synergistic [5]. Cypermethrin and some Cypermethrin - containing products are skin sensitizers. This means that when Cypermethrin is applied to skin several times, later application induces a more serious response than the first application [5]. Cypermethrin has caused the cornea of laboratory animals to be opaque. Exposure of pregnant laboratory animals to Cypermethrin can affect their offspring. Feeding pregnant rabbits with Cypermethrin resulted in a small increase in the number of organs and skeletal abnormalities in their offspring [5]. Rats exposed prenatally showed developmental delays: events such as the emergence of a tooth, opening of eyes, and development of particular reflexes delayed in occurrence up to three days [5]. Cypermethrin is also a skin and eye irritant, slight to severe skin irritation, decreased food consumption, body weight and absolute and relative gonad weights have been observed in rabbits treated with Cypermethrin [6]. Besides generalized toxic effects of Cypermethrin, decreased number of implantation sites, number of viable fetuses and weight gain of fetuses in rabbits treated with Cypermethrin have been reported [7].

Histologically, changes were observed in ovary and uterine tissues which were more pronounced at higher doses [8]. In this case, ovaries of rabbits showed connective tissue proliferation in the cortex. There was glandular atrophy, congestion and sloughing of epithelium along with connective tissue proliferation in the uterine tissues, probably due to interference of Cypermethrin with adenosine triphosphate (ATP) pathway. Inhibition of ATP leads to impaired energy utilization leading to cell death and sloughing of epithelium [8]. Experiment on the effect on biochemical parameters of testes after administration of $(250 \mathrm{mg} / \mathrm{kg}$, P.0) of $\alpha$ - Cypermethrin in albino mice was reported to cause histologic changes in spermatogenic cells, like rupture of cell membrane, shrinkage in the nucleus, presence of stages of apoptosis, condensation of chromatin and decrease or absence of cytoplasmic organelles, as revealed by transmission electron microscopy (TEM) [9]. Aerosols of the pyrethroid insecticide Matox ${ }^{\circledR}$ has been reported to have toxic effect on male rats exposed to Matox ${ }^{\circledR}$ daily up to 2, 4 and 8 weeks. It was reported to cause a significant decrease in weights of testis, epididymis, seminal vesicle and prostate glands. The cytotoxic action has been suggested to be associated with a decrease in testicular index weight of male rats. Such decrease could also be linked to the reduced testosterone synthesis and disruption of normal androgen status [10]. The objective of this study was to investigate gross and histopathological lesions of Cypermethrin on the testes, pituitary gland and the accessory sexual glands of Yankasa rams.

\section{Materials and Methods}

\section{Study Location}

The research was carried out at the National Animal Production Research Institute (NAPRI) Shika, Ahmadu Bello University Zaria, which is situated in the Northern Guinea Savannah and lying between latitudes $11^{\circ}$ and $12^{\circ} \mathrm{N}$ and longitude $7^{\circ}$ and $8^{\circ} \mathrm{E}$, at an elevation of $650 \mathrm{~m}$ above sea level. The area has an annual rainfall of $1100 \mathrm{~mm}$ [11]. There are two seasons \{rainy season (May-October) and dry season (NovemberApril)\}.

\section{Experimental animals}

The animal experiments followed the principles of the Laboratory animal care [12]. Sixteen sexually-mature, healthy Yankasa rams aged 18 - 30 months and weighing 
between 21.5 - $46.5 \mathrm{~kg}$ with clinically normal genitalia were used. The rams were purchased from the open market in Sabua Local Government Area of Katsina State. They were acclimatized for two weeks at the Small Ruminant Research Programme Experimental Unit of NAPRI, after which they were judged to be in good health based on clinical findings, hematological and faecal examinations. They were housed at the Small Ruminant Research Programme Experimental Unit of NAPRI. The house was made of brick concrete pens with concrete floors. The rams were divided into two groups of eight each. They were given concentrate feed ad- libitum (cotton seed, maize offal, maize, wheat offal, bone meal and salt) in the morning and later in the evening; hay was made available during the day at intervals. The hay used was Digitaria simuthii, and water was given ad- libitum.

\section{Experimental design and treatment}

The 16 rams were divided equally into two groups (A and B) Group A served as the treatment group while group B served as the control. The animals were acclimatized for two weeks during which time blood and faecal samples were collected and analyzed for haemoparasites and helminths and treatments given where necessary.

Administration of 3\% Cypermethrin: The rams in group (A) were given Cypermethrin $(3 \%)$ at the dose rate of $3 \mathrm{mg} / \mathrm{kg}(0.1 \mathrm{ml} / \mathrm{kg})$ body weight, topically as pour-on. The control group (B) rams were given distilled water at the same dose rate of $0.1 \mathrm{ml} / \mathrm{kg}$ body weight topically as pour-on. These treatments were repeated every two weeks for a period of 12 weeks.

Body measurements: The animals were weighed before sacrifice using a scale (Salter suspended weigher, model 235, UK). Their rectal temperatures (using a clinical thermometer) and respiratory rates (using stop watch) were taken concurrently to ascertain their health status.

\section{Sample collection and analysis}

The rams were sacrificed at the end of 12 weeks and the following organs (testes, pituitary, vesicular and prostate glands), were collected for histopathology. Eight testes, four from each group were collected for histopathology.

Gross and histopathological examination: Four rams each from groups A and B were sacrificed and the testes were removed intact then dissected from any extraneous tissue. The tunica albuginea was removed using a scapel blade and the testicular parenchyma was weighed. Gross pathological lesions were observed and photographs were taken. The testicular samples were immersed in $10 \%$ formalin for 24 hours and later were transferred to Bouin's solution and kept for histopathology. The following organs (seminal vesicles, prostate, pituitary glands,) were removed by dissection from all the rams and photographs were taken. The brain and the pituitary, were gently removed from the cranial cavity and properly cleaned off the meninges [13]. The brain was then immersed in $10 \%$ formalin for 24 hours and later transferred to Bouins' solution and kept for at least 2 - 3 weeks. The pituitary was dissected out, weighed and kept for gross and histopathology. Seminal vesicles, prostate, pituitary glands, were weighed and stored in $10 \%$ formalin for histopathology. Gross pathological lesions were noted immediately after dissection from the rams and photographs were taken.

Histological procedure: Routine H \& E (Haematoxylen and Eosin) staining method (general method) was used. The fixed tissues were trimmed and placed in the plastic or metal capsules with labels. They were dehydrated through series of graded alcohols $(70 \%, 80 \%, 90 \%, 95 \%$ and $100 \%)$ and cleared in xylene and then infiltrated with molten paraffin wax. Sections $(5-6 \mu \mathrm{m})$ microns thick were cut from embedded tissue using Jung Rotary Microtome (Model 42339). The tissues were mounted on clean, grease free glass slides stained with Hematoxylin and Eosin (H \& E) as standard 
procedure at room temperature. The prepared slides were studied using binocular light microscope (Olympus Binocular Microscope). At the Histopathology Laboratory of the Department of Veterinary Pathology, Faculty of Veterinary Medicine, Ahmadu Bello University, Zaria. Photomicrographs were captured, labeled and documented.

\section{Statistical analyses of data}

Data were expressed as means and Standard Error of Mean (SEM). Data were analyzed using descriptive statistics and paired student's t-test with SPSS/PC computer program (Version 20.0, SPSS ${ }^{\circledR}$, Chicago IL, USA). Differences with confidence values of $\mathrm{p}<0.05$ were considered statistically significant (Daniel, 1991).

\section{Results}

\section{Gross pathology of the pituitary and accessory sexual glands}

There were no gross pathological lesions found on the pituitary, prostate glands and the seminal vesicles of both the treated and control groups. The mean weight of the pituitary and accessory sexual glands examined for the treated and control groups are presented (Table 1), the differences were statistically not significant $(P>0.05)$.

\section{Gross pathology of the testes of both the treated and control rams}

No gross lesions were found on both the testes of the treated and control groups. The mean testicular weight for the treated and control groups after sacrificing the animals are presented (Table 1). The mean testicular weights of the treated and the control were significantly different $(\mathrm{P}<0.05)$.

\section{Histopathology}

Histologic sections of the testes of the control group showed seminiferous tubules with adequate amount of spermatogenic cells up to mature or late spermatids. Basically, the testes were normal (Figure 1). Similarly, the testes of the treated group showed seminiferous tubules with adequate amount of spermatogenic cells up to mature spermatids and not many spermatozoa but basically were normal (Figure 2). There was a reduced number of spermatozoa in the lumen of the seminiferous tubules

Table 1: Live weight of rams during sacrifice, weight of testes, pituitary gland, Prostate glands and seminal vesicles of Yankasa rams after sacrifice.

\begin{tabular}{|c|c|c|}
\hline Parameters & $\begin{array}{c}\text { Treated } \\
\mathbf{n = 4}\end{array}$ & $\begin{array}{c}\text { Control } \\
\mathbf{n}=\mathbf{4}\end{array}$ \\
\hline Pituitary weight $(\mathrm{g})$ & $0.47 \pm 0.04$ & $0.50 \pm 0.07$ \\
\hline Prostate glands weight $(\mathrm{g})$ & $7.45 \pm 1.88$ & $5.55 \pm 1.54$ \\
\hline Seminal vesicles (weight) $(\mathrm{g})$ & $5.20 \pm 1.25$ & $3.30 \pm 0.37$ \\
\hline Live weight $(\mathrm{kg})$ & $29.80 \pm 1.40$ & $26.30 \pm 1.30$ \\
\hline Testicular weights $(\mathrm{g})$ & $143.81 \pm 7.71^{\mathrm{a}}$ & $130.43 \pm 0.63^{\mathrm{b}}$ \\
\hline
\end{tabular}

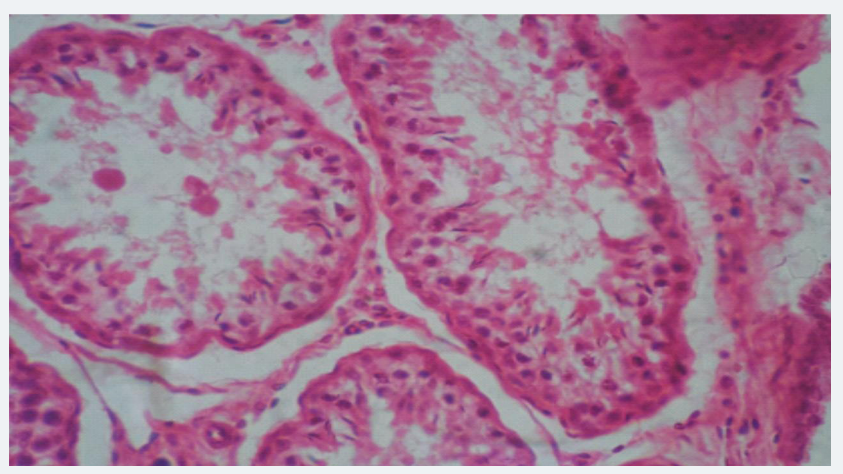

Figure 1: Photomicrograph of testis of control group: Seminiferous tubules with adequate amount of spermatogenic cells, up to mature or late spermatids, basically normal (x400)(H\&E) stain. 


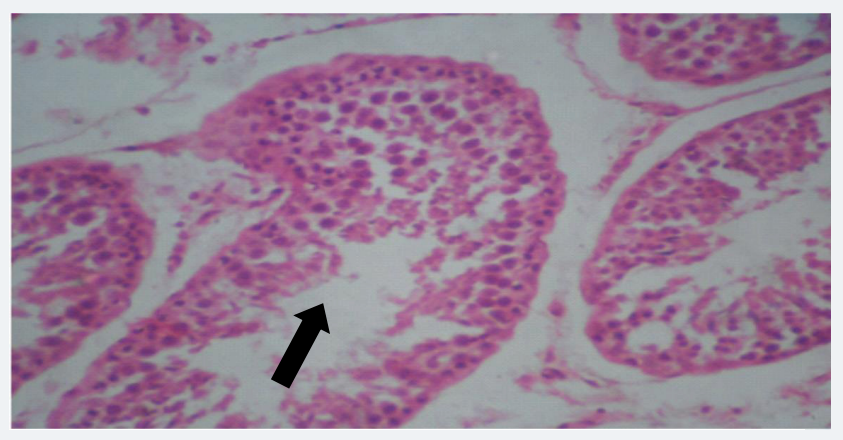

Figure 2: Photomicrograph of testis of treated group: Seminiferous tubules with adequate amount of spermatogenic cells, up to mature spermatids and not many spermatozoa, basically normal (x400) (H\&E) stain.

of the treated group compared to the control group. Histologic sections of the seminal vesicles of the control group showed normal epithelium. Similarly, seminal vesicles of the treated group showed normal epithelium. Histologic sections of the prostate glands of the control group showed normal epithelium, in the same manner the histologic sections of the prostate glands of the treated group showed normal epithelium. Histologic sections of the pituitary gland of the control group showed no evidence of lesions in the different pars distalis, intermedia + tuberalis and nervosa. The treated group equally did not show evidence of lesions in the different parts.

\section{Discussion}

Gross pathological studies of the testes, the accessory sex glands and the pituitary gland revealed no gross lesions in the treated rams. Again, weight measurement of the testes revealed that testicular weight was statistically significantly higher in treated rams than in the control rams. The weights of the accessory sex glands dissected for pathological studies in this particular rams, revealed that the weight of the prostate and seminal vesicle had higher values in the treated than in the control although the differences were not statistically significant. Live weight had higher values in the treated rams, though the differences were not statistically significant. Weight of the pituitary gland had lower values in the control rams. The higher values observed in the weights of the testes, prostrate and seminal vesicle in the treated rams may be relative to the live weight of the rams which was higher in treated than in control rams. The sizes of these organs are related to the body weight of rams. However a unique discovery in the measurements is that testicular weight is significantly higher in the treated rams.

This finding is in accordance with reports of Jalal etal. [14], Ingestion of Cypermethrin at high doses (18.93 or $39.66 \mathrm{mg}$ per day) resulted in a significant increase in the weights of testes and seminal vesicles of male Sprague Dawley rats [14]. In contrast, Wang et al. [15], reported that Cypermethrin decreases testicular weight and the weight of the male sexual accessory glands. Three doses of beta - Cypermethrin decreased body weight gain and weight of testosterone-sensitive organs such as testes, epididymis, seminal vesicles and prostate $[15,16]$. Cytotoxic effects of aerosols of the pyrethroid insecticide Matox $^{\circledR}$ on male rats exposed to Matox ${ }^{\circledR}$ daily up to 2, 4 and 8 weeks, which exhibited a significant decrease in weights of testes, epididymis, seminal vesicle and prostate glands have been reported [17]. Histologically, the testes of the treated rams showed seminiferous tubules with adequate amount of spermatogenic cells up to mature or late spermatids but not many spermatozoa, which was basically normal. It differed from the control group by having lower spermatozoa density. This observation corroborates the work of Wang et al. [15], where qualitative analyses revealed that low dose (1mg/ $\mathrm{kg}$ ) of beta-Cypermethrin decreased the number of interstitial Leydig cells but did not affect the intratubular compartment of seminiferous tubules, as the concentration of beta- Cypermethrin increased, the number of spermatids and cells in the seminiferous tubules appeared to decrease; moreover, some cells began to slough. At the high beta- 
Cypermethrin dose, only vacuolized primary spermatocytes were observed. All types of spermatids were nearly absent from the lumen of the seminiferous tubules. This observation shows that Cypermethrin caused testicular spermatozoa concentration reduction. In our studies $3 \mathrm{mg} / \mathrm{kg}$ body weight over three month period could have built up a concentration that started affecting the sperm cells within the seminiferous tubules and this reflected in the reduced number of spermatozoa within the lumen of the seminiferous tubules of treated rams. This observation is in line with the report that Cypermethrin treatment led to decrease in the epididymal sperm reserves at the caudal segment and significant decrease in the sperm concentrations of the treated rams [18]. Concentration of Cypermethrin in the body may not just depend on the dose but also on the duration of exposure [18]. Cypermethrin is also a skin and eye irritant. Slight to severe skin irritation, decreased food consumption, body weight and absolute and relative gonad weights have been observed in rabbits treated with Cypermethrin [6].These conflicting reports on the effect of Cypermethrin on testicular weight and the accessory sexual glands may be attributed to inaccurate interpretation since the weight of these organs are related to the live weight of the animals. Secondly, dose rate may be an important factor determining the outcome of the effect and finally, the species of animals involved in the study may be important.

In other studies involving laboratory animals, there have been report of dosedependent effects of Cypermethrin on the testicular index, weight etc. Oral administration of Cypermethrin at a dose of $55.1 \mathrm{mg} / \mathrm{kg}$ body weight $\left(1 / 5 \mathrm{LD}_{50}\right)$ for 60 successive days to male white rats induced deleterious effects on male fertility as elucidated by the significant decrease in testicular index, weight, sperm mass motility and sperm concentration in the epididymis [19]. In conclusion Cypermethrin did not cause any gross pathological lesions on the testes, pituitary gland, seminal vesicles and prostate glands of Yankasa rams. Cypermethrin reduced spermatozoa within the lumen of the seminiferous tubules of Yankasa rams. Histologically, the pituitary, prostate glands and seminal vesicles of Yankasa rams did not show any evidence of lesions following Cypermethrin treatment. It was recommended that more investigations be done to understand the mechanism by which Cypermethrin affects spermatozoa in the lumen of the seminiferous tubules.

\section{References}

1. He F. Neurotoxic effect of insecticides current and future research: A review. Neurotoxicology. 2000; 21: 829-835. Ref.: https://tinyurl.com/y94zkzwe

2. Barlow SM, Sullivan FM, Lines J. Risk assessment of the use of deltamethrin on bed nets for the prevention of malaria. Food and Chemical Toxicology. 2001; 39: 407-422. Ref.: https://tinyurl.com/yboe94to

3. Sandhu HS, Brar RS. Textbook of Veterinary Toxicology, $1^{\text {st }}$ ed. Kalyani Publ, New Dehli, India. 2000; 225-235.

4. Ullah MS, Ahmad M, Ahmad N, Khan MZ, Ahmad. Toxic effects of Cypermethrin in female rabbits. Pakistan Veterinary Journal. 2006; 2: 193-196. Ref.: https://tinyurl.com/yc64f734

5. Caroline C, Insecticide fact sheet. Journal of Pesticide Reform/Summer. 1996; 16: 1-20. Ref.: https://tinyurl.com/y9gbv2vf

6. Handerson HK, Parkison FN. Effect of Cypermethrin on haematology, clinical chemistry and gonads of male rabbit. Vet Med J (Giza). 1981; 31: 32-37.

7. Elbetieha A, Da'as SI, Khamas W, Darmani H. Evaluation of the toxic Potentials of Cypermethrin pesticide on some reproductive and fertility parameters in the male rats. Archives of Environmental Contamination and Toxicology. 2001; 41: 522-528. Ref.: https://tinyurl.com/y8xjv3k2

8. El-Toukhy MA, Girgis RS. In vivo and in vitro studies on the effect of Larvin and Cypermethrin on adenosine triphosphastase activity of male rats. Arch Environ Contam Toxicol. 1993; 28: 599-619. Ref.: https://tinyurl.com/y6ut6vjq

9. Prakash N, Kumar VM, Sunichandra U, Pavithra BH, Pawar A, et al. Evaluation of testicular toxicity following short-term exposure to Cypermethrin in albino mice. Toxicol International. Society of Toxicology. 2010; 17: 18-21. Ref.: https://tinyurl.com/yb7gdnol 
10. Abd-Allah AEY. Effect of some pesticides on reproduction. Ph.D. Thesis (Toxicology) Faculty of Veterinary Medicine, Cairo University. 1995.

11. Igono M, Molokwu EC, Aliu YO. Body temperature responses of Savanah Brown goats to hamattan and hot-dry seasons. Int J Biometeorology. 1982; 26: 225-230. Ref.: https://tinyurl.com/ycstowwm

12. Canadian Council on Animal Care Guide. 1993.

13. Harper JW, Maser JD. A macroscopic study of the brain of bison, the American plain buffalo. Anatomical Record. 1976; 18: 187-202. Ref.: https://tinyurl.com/ybkmpal6

14. Jalal S, Ramin H, Roohollah TZ. Effect of Cypermethrin on sexual behaviour and plasma concentrations of pituitary gonadal hormones. International Journal of Fertility and Sterility. 2010; 4: 23-28. Ref.: https://tinyurl.com/yd7lfkof

15. Wang XZ, Liu SS, Sun Y, Wu JY, Zhou YL $\beta$ - Cypermethrin impairs reproductive function in male mice by inducing oxidative stress. Theriogenology. 2009; 72: 599-611. Ref.: https://tinyurl.com/y84mao96

16. Hassan AB, Saliman GA, Farag AA, Sobbhy HM. Effect of the synthetic pyrethroids Sumicidin and S-3206 on male rat fertility. Veterinary Medical Journal, Giza. 1993; 41: 33-38. Ref.: https://tinyurl.com/y9mwk74l

17. El-Ashmawy IM, Zakaria AD, Hemed SM, El -Fikey S, Hussein YA. Cytotoxic effects of the pyrethroid insecticide (Matox) with reference to its influence on the reproductive hormone. Veterinary Medical Journal. Giza. 1993; 3: 125-130. Ref.: https://tinyurl.com/y8bq8ufh

18. Ubah SA, Ogwu D, Rekwot PI, Rwuaan, JS, Chibuogwu IC. Gonadal and epididymal sperm reserves of Yankasa rams treated with Cypermethrin. American Journal of Biomedical and Life Sciences. 2016; 4: 16-20. Ref.: https://tinyurl.com/y89gud25

19. Assayed ME, Salem HA, Khalaf AA. Protective effects of garlic extract and vitamin C against Cypermethrin reproductive toxicity in male rats. Research Journal of Veterinary Science. 2008; 1 1-5. Ref.: https://tinyurl.com/y88t9nt9

20. Daniel WW. Analysis of variance. In: Daniel WW (Ed) Biostatistic: A Foundation for Analysis in the Health Sciences. John Wiley \& Sons, Hoboken. 1991; 74-320. 